\title{
Mechanism of insulin resistance in obesity: a role of ATP
}

\author{
Jianping Ye (凶) \\ Shanghai Diabetes Institute, Shanghai Jiao Tong University Affiliated Sixth People’s Hospital, Shanghai 200233, China
}

(C) The Author(s) 2021. This article is published with open access at link.springer.com and journal.hep.com.cn

\begin{abstract}
Obesity increases the risk of type 2 diabetes through the induction of insulin resistance. The mechanism of insulin resistance has been extensively investigated for more than 60 years, but the essential pathogenic signal remains missing. Existing hypotheses include inflammation, mitochondrial dysfunction, hyperinsulinemia, hyperglucagonemia, glucotoxicity, and lipotoxicity. Drug discoveries based on these hypotheses are unsuccessful in the development of new medicines. In this review, multidisciplinary literature is integrated to evaluate ATP as a primary signal for insulin resistance. The ATP production is elevated in insulin-sensitive cells under obese conditions independent of energy demand, which we have named "mitochondrial overheating." Overheating occurs because of substrate oversupply to mitochondria, leading to extra ATP production. The ATP overproduction contributes to the systemic insulin resistance through several mechanisms, such as inhibition of AMPK, induction of mTOR, hyperinsulinemia, hyperglucagonemia, and mitochondrial dysfunction. Insulin resistance represents a feedback regulation of energy oversupply in cells to control mitochondrial overloading by substrates. Insulin resistance cuts down the substrate uptake to attenuate mitochondrial overloading. The downregulation of the mitochondrial overloading by medicines, bypass surgeries, calorie restriction, and physical exercise leads to insulin sensitization in patients. Therefore, ATP may represent the primary signal of insulin resistance in the cellular protective response to the substrate oversupply. The prevention of ATP overproduction represents a key strategy for insulin sensitization.
\end{abstract}

Keywords type 2 diabetes; energy expenditure; mitochondria; hyperinsulinemia; hyperglucagonemia; AMPK

\section{Introduction}

Insulin is a hormone with a physiologic role in energy storage, which includes activities in the induction of glucose uptake, glycogen, and lipid synthesis in peripheral tissues. The effect and inhibition of gluconeogenesis in liver are responsible for the reduction in blood glucose by insulin. Insulin stimulates glucose conversion into other forms of energy, such as fatty acids, amino acids, and cholesterols, in addition to glycogen through anabolism for energy storage. Additionally, insulin induces synthesis and inhibits the breakdown of energy-containing molecules (e.g., glycogen, triglycerides, and proteins) to attenuate energy mobilization in favor of energy storage. The inhibition contributes to the suppression of the gluconeogenesis process through the minimal production of glucogenic substrates, such as lactate, glycerol, and

Received January 9, 2021; accepted April 25, 2021

Correspondence: Jianping Ye, yejianping@sjtu.edu.cn amino acids. According to this line of insulin activities, cells are sensitive to insulin in energy-deficient conditions to enhance energy storage and insensitive to insulin in energy-surplus conditions to prevent burden. On this basis, the insulin sensitivity is an "index of energy demand" that is positively associated with energy requirement in cells. A high demand promotes insulin sensitivity, whereas a low demand decreases insulin sensitivity. The demand is determined by the balance of supply and consumption of energy substrates. The energy consumption rate includes the energy expenditure rate in catabolism and energy storage rate in anabolism, thereby controlling the cellular energy demand. The systemic insulin sensitivity is an index of energy demand in the whole body.

Insulin resistance is a condition of the persistent loss of insulin sensitivity, whose molecular mechanism is the impairment of the insulin signaling pathway downstream of the insulin receptor. Insulin resistance, which is characterized by hyperinsulinemia together with hyperglycemia, occurs frequently in subjects with obesity and aging. In laboratory tests, insulin resistance is diagnosed 
by several parameters, including impaired insulin tolerance, decreased glucose infusion rate, increased hepatic glucose production, hyperinsulinemia with hyperglycemia, and loss of the first-phase secretion of insulin. In pathophysiology, insulin resistance is closely associated with the following factors [1]: (1) genetic background, (2) aging, (3) hyperlipidemia, (4) fatty liver, (5) pregnancy, (6) polycystic ovary syndrome [2], (7) lipodystrophy, (8) stress, (9) chronic inflammation, and (10) mitochondrial dysfunction. Many of these factors are directly associated with weight gain or obesity from energy overintake or inadequate energy expenditure. In the aging condition, a reduction in energy demand is a major factor for energy surplus. Therefore, insulin resistance is a status of energy surplus.

The energy surplus may induce insulin resistance through the activation of many signaling pathways. In current concepts, the signaling molecules of insulin resistance include serine kinases (such as JNK, IKK, PKC, and Akt/mTOR/S6K), reactive oxygen species (ROS), diglycerides (DAGs), and ceramide $[3,4]$. These factors trigger insulin resistance by the inhibition of signaling molecules downstream of the insulin receptor $[1,3]$. However, strategies on targeting these molecules have not been successful in drug development in the field of diabetic medicines [3,5]. Here, we would like to take an alternative approach to address the signals of energy surplus with a focus on the signaling activities of metabolites of energy substrates, such as ATP [1], $\mathrm{NADH}$ [6], and acetyl-CoA [3]. These metabolites are indicators of energy status in insulin-sensitive cells. Their elevation leads to insulin resistance in a feedback manner to protect cells from mitochondrial overloading by glucose and fatty acids to restrict the elevation of metabolites. This "energy-centered view" of insulin resistance is supported by the basic principle of biochemistry, laboratory studies, and clinical outcomes of various therapeutics. The view is explained below to provide a unifying molecular mechanism for insulin resistance in obesity and aging.

\section{ATP as a signal of energy surplus for insulin resistance}

Intracellular ATP is the primary energy currency in cells, and its elevation is a risk factor of insulin resistance [7]. This concept has a history of around 60 years [8], but its importance has not been well appreciated due to difficulties in the real-time quantification of ATP in tissues. In the past few years, the ATP elevation has been observed in the study of energy surplus signals in human and mouse by using the luciferase-based ATP assay technology. In a human study about the effect of acute overfeeding on insulin sensitivity, the elevation is observed in the liver [9]. In mice with diet-induced obesity (DIO), elevation is observed in fat [10], liver [11,12], and intestine [13,14]. Elevation induces ATP/ADP and ATP/AMP ratios, which provide a perfect mechanism for the reduced AMPK activity in the liver/muscle of obese rodents and patients $[1,15]$. The AMPK activity is decreased in the conditions of insulin resistance with reduction in the AMPK phosphorylation status (T172) and AMPK proteins [1618]. The protein reduction is investigated in the cellular models of glucose stimulation, and the mechanism is ubiquitin-mediated protein degradation after glucoseinduced ROS [18]. Mitochondrial overloading by the energy substrates, such as glucose, fatty acid, and amino acid, is a primary cause of insulin resistance in the skeletal muscle through mitochondrial dysfunction, mitochondrial inflexibility, and activation of the mTOR/S6K pathway $[3,19,20]$. The effect of fatty acid overloading is well documented for the insulin resistance of skeletal muscle through metabolic inflexibility [21]. Here, ATP is considered one of the signals derived from the substrate overloading for metabolic inflexibility. Other signals include ROS, DAG/PKCs, ceramides/JNKs, mTOR/S6K, and ER stress $[3,4]$. However, the role of ATP remains to be tested in the overloading model. The study is hampered by the lack of ATP-sensing technology in the past. New ATP-responsive fluorescent probes have been reported recently [22,23], thereby making such a study feasible in vitro and in vivo. The reduction in ATP production is observed in cells under nutrition-deficient conditions in the cell culture by using one of the probes (ATP-Red 1) [23]. The translation of the technology into the in vivo study will facilitate the ATP study in terms of insulin resistance.

The ATP concept is supported by the basic principle of biochemistry. In the classical concept of physiology, the ATP production is driven by energy demand in the cells of the skeletal muscle or cardiomyocytes [24,25]. In the absence of demand, the ATP production is maintained at a low level, and anabolism is dominant for energy storage by the synthesis of glycogen, triglycerides, and proteins. When the energy storage reaches the limitation in cells under obese conditions, anabolism is subject to a negative feedback by the final products according to the principle of biochemistry. However, the identity of the final product remains unclear. In response to the substrate overloading, catabolism is activated to reduce the loading pressure through the activation of the mitochondrial function, which occurs in the model of high-fat diet feeding with elevated oxygen consumption in animals [26,27]. A high-fat diet promotes mitochondrial catabolism even at the isocaloric condition in the absence of overeating [27]. The metabolic enzymes of mitochondria are activated by intermediate metabolites, leading to the overproduction of ATP in the absence of energy demand in cells. We have called this process "mitochondrial overheating" to explain the disassociation of energy demand and production in cells in obese conditions [14]. The view extends the 
demand-driven ATP production in the classical concept of physiology [24].

In addition to ATP production, mitochondria may release energy through thermogenesis. Heat production is increased together with ATP production in the mitochondria due to the nature of mitochondrial respiration at about $50 \%$ coupling efficiency [28]. Heat may lead to temperature elevation inside the mitochondria. The substrate loading increases ATP and heat production in the mitochondria, which is demonstrated in cell cultures with fluorescent ATP probes [22,23] and in HFD feeding models $[26,27]$. In cell culture studies, fluorescent ATP probes are tested in monitoring intracellular ATP levels. A high level of glucose in the culture medium is coupled with increased ATP production by mitochondria and elevation of intracellular ATP in studies. A low concentration of glucose is coupled with minimal ATP production by the mitochondria in cellular studies, which suggests the positive relationship of substrate supply and ATP production in the mitochondria. Heat may serve as another signal in the feedback regulation. A high temperature is associated with a high level of catabolism and energy demand in the human body under fever [29]. Given that ATP and heat production is coupled together in the mitochondria [28], the temperature elevation may promote increased production of ATP and heat by increasing enzyme activities. Substrate overloading is the basis of ATP overproduction in obese conditions and precedes insulin resistance through several signaling pathways as discussed below.

The ATP concept is supported by substantial evidence in basic and clinical studies. Some evidence is as follows: (1) enhanced mitochondrial function in $\beta$-oxidation leads to insulin resistance in the lipid infusion model [30,31], and the inhibition of $\beta$-oxidation with pharmacological inhibitors (etomoxir or oxfenicine) prevents the lipidinduced insulin resistance in rodents [32,33]; (2) the induction of mitochondrial function is associated with the insulin resistance of transgenic mice fed on a high-fat diet $[32,33]$. The luciferase-based ATP assay technology has shown that the ATP elevation is observed in fat [10], liver $[11,12]$, and intestine $[13,14]$ in obese mice with insulin resistance. In the human study, the elevation is observed in the liver along with insulin resistance in a study of acute overfeeding [9]. Elevation in the ATP/ADP and ATP/AMP ratios provides a perfect mechanism for the fallen AMPK activity in obese rodents and patients [1,16-18]. In addition, the ATP concept is supported by the broad indirect evidence in clinical and laboratory studies. The control of mitochondrial overloading leads to insulin sensitization in the following conditions: (1) weight loss through calorie restriction [10], bypass surgeries [34], SGLT2 inhibitors [35], and GLP-1 analogs [35]; (2) reduction in ATP production by targeting the respiration chain of mitochondria with medicines, including metformin [36], berberine [37,38], mitochondrial uncouplers [39-41], and gene mutation [32,33]; and (3) depletion of ATP by physical exercise. The literature strongly supports the ATP concept although some studies suggest that ATP is not elevated by the substrate oversupply [18]. However, the proof of concept needs a real-time test of intracellular or intramitochondrial ATP levels in vivo. New ATP fluorescent probes $[22,23]$ make it possible to test the ATP levels in these models. The ATP-Red 1 probe has been used to quantify the ATP level in mitochondria in living cells [23]. Therefore, the control of ATP balance is a key strategy in the correction of insulin resistance.

ATP elevation may contribute to insulin resistance through the induction of mitochondrial dysfunction by the inhibition of two events in the mitochondria, i.e., biogenesis and mitophagy. Mitochondrial dysfunction is reported in the heart and skeletal muscle in subjects with insulin resistance $[42,43]$. Dysfunction leads to a reduction in the mitochondrial production of ATP, a result of decreased utilization of glucose by mitochondria. The reduced glucose utilization is coupled with insulin resistance in the skeletal muscle of patients with type 2 diabetes. Glucose metabolites, such as pyruvate, is used in several metabolic pathways in the mitochondria, including ATP production and biosynthesis of fatty acids and amino acids through acetyl-CoA. These activities are impaired by mitochondrial dysfunction during insulin resistance. Mitochondrial biogenesis and mitophagy are two events in the maintenance of the quality and quantity of mitochondria in the prevention of mitochondrial dysfunction. These events are inhibited when the ATP supply is more than the ATP demand in cells, leading to mitochondrial dysfunction. The ATP elevation may generate the effects by inhibition of AMPK $[43,44]$. Therefore, the ATP surplus is an excellent risk factor for the mitochondrial dysfunction and insulin resistance. Once mitochondrial dysfunction occurs, ATP production is reduced as documented in the mechanism of diabetic complications [45].

\section{ATP contributes to insulin resistance through the suppression of AMPK}

ATP may use multiple signaling pathways to generate an integrated signal in the regulation of insulin action. Among these pathways, the AMPK signaling pathway is the most relevant for its role in the energy-sensing system. AMPK is an energy sensor that is activated upon ATP reduction through the decrease in ATP/AMP or ADP/AMP ratio in the cytoplasm. In addition to ATP, glucose is sensed by the AMPK in the cytoplasm [46] and calcium and DNA damage [47]. In energy-surplus conditions, the AMPK activity is downregulated, leading to a fall in fuel supply to mitochondria through the alteration in several events in cells, such as reduction in glucose and fatty acid uptake, 
suppression of glycogenolysis and lipolysis in the cytoplasm, and reduction in mitochondrial function. AMPK has at least 60 downstream targets in the control of energy metabolism [47]. In the insulin signaling pathway, AMPK inhibits mTOR/S6K and activates Glut4. In the presence of ATP surplus, a fall in the AMPK activity leads to the downregulation of Glut4 activity for the inhibition of insulin-stimulated glucose uptake in the mechanism of insulin resistance. AMPK is inhibited in obesity by the rise in ATP/AMP or ADP/AMP ratio, as documented in reviews [17,47-49]. The reduced glucose uptake from the AMPK suppression contributes to blood glucose elevation in obesity and type 2 diabetes. Interestingly, the AMPK activity in the control of insulin sensitivity may apply to most tissues but not to the skeletal muscle. The inactivation of AMPK by the $A M P K \alpha 2$ gene knockout $(\mathrm{KO})$ leads to insulin resistance in most tissues of mice but not in the skeletal muscle [50]. In addition to glucose uptake, glucose metabolism is regulated by AMPK through an impact in multiple aspects of mitochondria. Mitochondrial biogenesis and quality control are two examples. AMPK promotes mitochondrial biogenesis through the phosphorylation of PGC- $1 \alpha$ in energydeficient conditions. In energy-surplus conditions, the inhibition of the AMPK/PGC-1 pathway leads to the suppression of mitochondrial biogenesis and reduction in mitophagy to decrease the number and quality of mitochondria $[43,51]$. A long-term inhibition of the two events results in mitochondrial dysfunction. The AMPK pathway provides a perfect mechanism for mitochondrial dysfunction [52] and inflexibility [53], in the conditions of obesity, aging, and type 2 diabetes $[1,43]$. As one of the signaling molecules, AMPK may not be essential for the signal transduction of ATP in all tissues, as suggested by the $A M P K \alpha 2$ gene KO study [50].

Intracellular ATP may use other signaling pathways in the regulation of insulin sensitivity in addition to AMPK $[1,3]$. The signaling pathways, such as mTOR/S6K, ROS/ JNKs, and DAG/PKCs, are activated by obesity and documented in the mechanism of insulin resistance $[3,4]$. The mTOR/S6K activity is activated by insulin, which has been reported in the negative feedback regulation of the insulin signaling pathway $[54,55]$. In addition to insulin, nutrients (such as branched-chain amino acids) activate the $\mathrm{mTOR} / \mathrm{S} 6 \mathrm{~K}$ pathway for insulin resistance [56]. Interestingly, intracellular ATP may activate mTOR in a couple of ways. ATP may activate mTOR through the inhibition of AMPK activity because mTOR is activated in the presence of AMPK inhibition [57]. Additionally, mTOR is activated directly by ATP in the cell lysate in the test tube [58]. ATP may activate mTOR through the induction of GTP, a derivative of ATP in cells [47]. ATP interacts with many enzymes, such as AMPK and mTOR. These studies suggest that ATP may induce insulin resistance through multiple signaling pathways involved in numerous enzymes, including signaling kinases and metabolic enzymes. This possibility explains why the strategy targeting one of those enzymes at downstream of ATP is not successful in the drug development for insulin resistance. Instead, the inhibition of ATP surplus by metformin or substrate restriction (through calorie restriction and metabolic surgery) is effective in the improvement of insulin sensitivity.

\section{ATP contributes to insulin resistance through hyperinsulinemia}

ATP may contribute to insulin resistance through an extracellular activity in the body. The intracellular activity of ATP is discussed above. In this and the following sections, the activity of extracellular ATP will be discussed in the context of endocrinology. Hyperinsulinemia is an important risk factor for insulin resistance and an independent predictor of type 2 diabetes [54,59-62]. Hyperinsulinemia leads to insulin resistance through the negative feedback regulation of the insulin signaling pathway in insulin-sensitive cells. The inhibition of insulin receptor substrates (IRS-1/2) by serine phosphorylation is a representative molecular event in the negative feedback regulation by insulin [54,59,63], which involves S6K activation by mTOR and phosphorylation of IRS-1 by S6K. The biological importance of the insulin resistance under hyperinsulinemia is the prevention of life-threatening hypoglycemia in the body. The hypersecretion of insulin is a cause of hyperinsulinemia. The correction of the hypersecretion leads to the improvement of insulin sensitivity [61] and prevention of obesity [64]. Therefore, the insulin hypersecretion is a target in the treatment of insulin resistance.

ATP overproduction is a potential risk factor for the insulin hypersecretion in $\beta$-cells. In physiologic conditions, insulin is secreted by $\beta$-cells upon glucose challenge through an elevation in ATP production by mitochondria from glucose. In addition to this pathway, glucose induces NADPH and DAG and hormones (glucagon, GLP-1, and GIP) to promote insulin secretion [65]. Hormones act through their own receptors to activate the cAMP/PKA pathway to keep the $\beta$-cell sensitivity to glucose. The overactivation of pancreatic $\beta$-cells is responsible for insulin hypersecretion in obesity $[54,59,60,66]$. An increase in the $\beta$-cell number is a mechanism for hypersecretion $[59,60]$. However, an increase in the function of individual $\beta$-cell is also reported [61]. Several potential mechanisms are present for the function alteration. One is the increase in nutrient supply (such as glucose, amino acids, and fatty acids) from the overintake of calories. Another is the minimal inhibition of $\beta$-cell function by leptin due to leptin resistance [67]. However, nutrition oversupply is important for the hypersecretion by 
$\beta$-cells. Nutrients promote ATP production by mitochondria, increase DAG and NADPH supply, and raise cAMP levels through incretin hormones in $\beta$-cells. All of these changes may contribute to insulin hypersecretion in obesity.

Extracellular ATP represents an important factor in insulin hypersecretion. The role of extracellular ATP in the induction of insulin secretion has been documented in a previous review article [68]. ATP is presented in the insulin granule of $\beta$-cells at a concentration of around $25 \mu \mathrm{mol} / \mathrm{L}$ and secreted together with insulin to the extracellular matrix $[69,70]$. ATP secretion leads to the elevation of extracellular ATP in the pancreatic islet. The direct effect of ATP is observed in the cell culture, in which ATP induces insulin secretion by $\beta$-cells. The ATP effect is dependent on the purinergic receptors, $\mathrm{P} 2 \mathrm{X}$ and P2Y [68]. The activation of receptors induces $\mathrm{Ca}^{2+}$ and cAMP levels in the cytoplasm and promotes insulin secretion. The extracellular ATP may also inhibit insulin secretion by interaction with certain purinergic receptors. GABA and glutamate are also secreted together with insulin by $\beta$-cells. The ATP signal may be mediated by ADP in the regulation of $\beta$-cell secretion [68]. Additionally, ADP may regulate $\beta$ cell number through the control of apoptosis. The extracellular ATP forms a positive feedback regulation of $\beta$-cell function in pancreatic islets.

Intracellular and extracellular ATP induce insulin secretion in $\beta$-cells in physiologic studies as discussed above. The ATP activity remains to be established for the insulin hypersecretion in obesity. We propose that ATP overproduction may use intrinsic and endocrine pathways to induce hyperinsulinemia. The inhibition of the ATP overproduction represents a potential approach in the treatment of hyperinsulinemia and insulin resistance in obesity. This concept needs to be tested in laboratory and clinical studies.

The ATP concept may provide a new mechanism for metformin activity in the control of insulin resistance. Metformin is believed to improve insulin sensitivity through the activation of the AMPK pathway in the liver and skeletal muscle, which is involved in the inhibition of ATP production by metformin in the activation of AMPK [36,71]. Upon insulin sensitization, insulin secretion by $\beta$ cells is reduced to attenuate hyperinsulinemia. Metformin may use this pathway as an indirect mechanism in the control of hyperinsulinemia. Additionally, metformin may directly act on $\beta$-cells to reduce insulin secretion. Metformin inhibits ATP production in liver, and this activity may apply to $\beta$-cells. Metformin is reported to reduce glucotoxicity and lipotoxicity in $\beta$-cells in cell culture models $[72,73]$, thereby supporting the direct effect of metformin on $\beta$-cells. Metformin reduces ROS production by the downregulation of the mitochondrial respiration of $\beta$-cells. Such action should decrease insulin secretion by the pancreatic islet in vivo. However, data are not interpreted in this way in those studies [72,73]. Given that hyperinsulinemia is a risk factor for insulin resistance [54,59-62], the metformin effect on $\beta$-cells represents a key event in the pharmacological activity. If approved in the experiment, the $\beta$-cell-centered mechanism should stand for a new signaling pathway in the understanding of the therapeutic activity of metformin in type 2 diabetes. However, an early study suggests that metformin does not change the arginine-induced insulin secretion by the islet [74]. The metformin effect on glucose-induced insulin secretion should be tested.

A deficiency in insulin clearance may contribute to the hyperinsulinemia under ATP overproduction. The level of circulating insulin is determined by the degradation process in the insulin clearance system. The impaired clearance of insulin is another mechanism for hyperinsulinemia in obesity. In the insulin clearance mechanism, the insulin-degrading enzyme (IDE) is a primary factor, whose activity is increased in the liver of mice with DIO [75]. The IDE activity is further enhanced by the treatment of obese mice with insulin-sensitizing medicine pioglitazone. In the cultured hepatocyte cell line (1c1c7), the IDE activity is decreased by the inflammation cytokine TNF- $\alpha$. The ATP level is elevated in the liver of obese mice [11,12], which is associated with elevation in the IDE activity [75]. However, the exact role of ATP in the control of insulin clearance remains unknown. ATP may increase the TNF- $\alpha$ activity in the liver to inhibit the IDE activity for hyperinsulinemia in obesity. These results suggest that ATP may promote insulin clearance through the direct activation of DIE. ATP may indirectly inhibit IDE activity through the induction of proinflammatory cytokines. The intracellular ATP promotes the expression of proinflammatory cytokines, including TNF- $\alpha$ [10]. The possibility deserves to be tested with advanced models.

\section{ATP contributes to insulin resistance through hyperglucagonemia}

Hyperglucagonemia is a risk factor for type 2 diabetes [7678]. High levels of glucagon contribute to the pathogenesis of type 2 diabetes by the induction of hepatic insulin resistance, which leads to hyperglycemia through gluconeogenesis and glycogenolysis [76,77]. Additionally, glucagon may contribute to the hyperinsulinemia through the promotion of insulin secretion by $\beta$-cells because glucagon deficiency by $\alpha$-cell $\mathrm{Gcg}$ gene $\mathrm{KO}\left(\mathrm{Gcg}^{-/}\right)$ impairs insulin secretion by $\beta$-cells [77]. The inhibition of the glucagon activity in the liver is a mechanism of metformin [79] and GLP-1 [77] activities in the improvement of insulin resistance. GLP-1 may interact with the glucagon receptor to interfere the signaling in the liver for the inhibition of gluconeogenesis [77]. Glucagon has been a target molecule in the drug development for diabetes 
[77]. An antagonist (RVT-1502, formerly LGD-6972) of glucagon receptor is effective in the treatment of patients with type 2 diabetes by reducing $\mathrm{HbAlc}$ and fasting plasma glucose [80].

Glucagon is secreted by pancreatic $\alpha$-cells in response to the reduction in blood glucose and elevation of amino acids in the physiologic conditions [77]. The amino acid activity is stronger than glucose activity in the regulation of $\alpha$-cells. Among amino acids, glutamine, arginine, and alanine may induce 10-fold glucagon secretion at levels of $0.5-1.0 \mathrm{mmol} / \mathrm{L}$ in the blood. Amino acids act through the direct stimulation of $\alpha$-cells. The mechanism of low glucose remains elusive in the induction of glucagon secretion [77]. Glucagon secretion is controlled by intrinsic, paracrine, and nerve mechanisms. In intrinsic models, the glucagon secretion upon glucose reduction in the blood requires the activation of the cAMP/PKA pathway and voltage-dependent $\mathrm{Ca}^{2+}$ influx [81]. The signaling pathway is activated by adrenergic nerves through the $\alpha 2$-receptor on the surface of $\alpha$-cells [68]. The pathway is suppressed by the autonomic nervous system in the inhibition of glucagon secretion [81].

The paracrine regulation represents a major mechanism in the control of glucagon secretion [77]. A defect in the regulation may account for the hyperglucagonemia in type 2 diabetes. The glucagon secretion is inhibited by insulin and somatostatin (from $\delta$-cells) in the pancreatic islet [76]. The secretion is also inhibited by GABA [82] and induced by glutamate [83], which are secreted together with insulin from $\beta$-cells. Insulin and GABA suppress the glucagon secretion [76]. The suppression involves the downregulation of the cAMP/PKA signaling pathway and voltagedependent $\mathrm{Ca}^{2+}$ influx [84]. Insulin reduces cAMP in the cytoplasm through decreasing cAMP by induction of the hydrolysis enzyme. In type 2 diabetes, this inhibition is impaired in rodent models [76] and patients [85], thereby contributing to the glucagon hypersecretion and hyperglucagonemia. The mechanism underlying the impaired insulin action remains unknown. Plasma amino acids are elevated in obesity $[86,87]$, and the elevation may play a role in the hypersecretion of glucagon because plasma amino acids are strong inducers for glucagon secretion [77]. A failure in the negative feedback regulation likely contributes to the hypersecretion of glucagon. However, how the negative feedback is impaired for the glucagon hypersecretion remains unknown.

Extracellular ATP provides a potential mechanism for the feedback failure in the glucagon regulation. Extracellular ATP has drawn more attention in the mechanism of obesity and obesity-associated complications. The early review about extracellular ATP in the pancreatic islet does not cover obesity [68]. Obesity is covered in a recent review on the extracellular ATP in the adipose tissue and brain [88]. Unfortunately, the review does not discuss the extracellular ATP in the pancreatic islet. We would like to cover the ATP effect on $\alpha$-cells. In the pancreatic islet, ATP is secreted together with insulin to the extracellular matrix. Extracellular ATP may regulate glucagon secretion through the interaction with purinergic receptors. $\alpha$-cells express several types of purinergic receptors, including P2Y6, P2X7, and P2Y1 [68,89]. The activation of P2Y6 and $\mathrm{P} 2 \mathrm{X} 7$ increases glucagon release [68], which may explain the increased glucagon secretion in response to insulin secretion after food intake and glucose challenge [77]. The P2Y1 activation leads to the inhibition of glucagon secretion. Among the ATP receptors, the activation of $\mathrm{P} 2 \mathrm{X} 7$ by a pharmacological agent induces energy expenditure in mice [90], and the inactivation by gene $\mathrm{KO}$ does not change body weight and insulin sensitivity in KO mice [91]. However, this ATP-based pathway deserves to be explored further especially in the models of obesity.

ATP may act through ADP. ATP is not stable in the extracellular space and is hydrolyzed by enzymes to generate ADP and AMP. The secretion of ATP leads to the elevation of ADP in extracellular spaces, where ADP may bind to its receptor (P2Y13) on the surface of $\alpha$-cells. $\mathrm{P} 2 \mathrm{Y} 13$ is one of the $\mathrm{G}$ protein-coupled receptors in the adenosine receptor family, which contain several isoforms of ADP receptors (P2Y1, P2Y12, and P2Y13) [89]. The activation of the P2Y13 receptor may influence several signaling pathways, including cAMP/PKA and PI3K/Akt [92]. The P2Y13 activity has recently been tested in $\alpha-$ cells. Its activation by ADP leads to glucagon secretion from $\alpha$-cells, resulting in glucagon elevation in the blood and glucose rise in the circulation [93]. A report about the P2Y13 activity in $\beta$-cells in the regulation of insulin secretion, where the receptor activation by ADP inhibits insulin secretion in mice, is available [94]. This activity is not observed in mice with ADP injected peritoneally to raise the ADP level in the blood because the insulin level is not changed in the blood [93]. ADP is degraded by CD39, an ectoenzyme that is predominantly expressed in vascular endothelial and immune cells. The inhibition of the CD39 activity by gene $\mathrm{KO}$ increases the extracellular ADP. In the global CD39 gene KO mice, hepatic insulin resistance is reported [95]. KO mice exhibit hyperinsulinemia with insulin enrichment in $\beta$-cells. Glucagon is examined briefly in the study but not thoroughly because the focus is given to insulin in the mechanism study. Glucagon is examined in $\alpha$-cells by immunohistochemistry, and no significant change is observed in the tissue slide. A careful examination should be done in $\mathrm{KO}$ mice for the quantification of the protein and mRNA of glucagon. The CD39-KO mice have systemic inflammation for the rise in blood IL- $1 \beta$, IL-6, IFN- $\gamma$, and TNF- $\alpha$, which likely results in the CD39 inactivation in immune cells.

The activation of P2Y13 receptor by ADP triggers the cAMP/PKA pathways in retinal glial progenitors in the cell culture [96]. This P2Y13 pathway has not been reported in 
$\alpha$-cells. The activation of cAMP/PKA pathways by sympathetic neurotransmitters induces glucagon secretion in $\alpha$-cells. These facts suggest that P2Y13-KO mice should exhibit a reduction in glucagon secretion and an improvement in insulin sensitivity. The global inhibition of the $\mathrm{P} 2 \mathrm{Y} 13$ receptor by gene $\mathrm{KO}$ has been made in mice. Global P2Y13-KO mice do not exhibit any change in insulin sensitivity or glucose tolerance [97]. Given several types of ADP receptors [89], compensation by other receptor isoforms may offset the KO effect. Given that more than one receptor isoforms exist for ATP and ADP, using the genetic approach to test the roles of these purine derivatives in vivo is difficult. A pharmacological approach is more promising than the genetic approach in the study of ATP activity. The role of extracellular ATP remains to be tested in the control of glucagon production.

\section{ATP surplus in aging-associated insulin resistance}

Type 2 diabetes has a high prevalence in aging people from insulin resistance, which is often associated with central obesity, imbalance of sex hormone, and lack of physical activities. In these conditions, oxidative stress and mitochondrial dysfunction have been proposed in the mechanism of insulin resistance [52,98-100]. However, these hypotheses remain to be approved. We propose that like that in obesity, ATP surplus is the key event in the aging-associated insulin resistance as most treatments for obesity-associated insulin resistance are effective in the treatment of aging-associated insulin resistance. The reduction in intracellular ATP is a key event in the underlying mechanism of treatments discussed above. Oxidative stress and mitochondrial dysfunction may be a result of mitochondrial overheating in ATP production.

\section{ATP surplus in gene background- associated insulin resistance}

The gene background is a key factor in the pathogenesis of insulin resistance. This finding is supported by several lines of evidence. The first is that patients with insulin resistance or the high-risk population often have a family history of type 2 diabetes. The second is the high risk of insulin resistance in certain ethnic populations, as shown by epidemiology studies. Central obesity, mitochondrial dysfunction, hypoadiponectinemia, and inflammation have been proposed to link the gene background to insulin resistance [1]. Given that mitochondrion-related genes have a high incidence in diabetes-related genes, the ATP overproduction in these gene backgrounds may count for the risk of insulin resistance. This possibility is supported by the association of high ATP production and high susceptibility to insulin resistance in Asian Indians [101] and DIO mice [24].

\section{Summary}

Obesity and aging increase the risk of type 2 diabetes through energy surplus. The identity of energy surplus signal remains to be established. Here, we provide a new view to support ATP as a signal of energy surplus in the mechanism of insulin resistance by integration of multidisciplinary evidence in the literature. The ATP concept in insulin resistance redefines the biological importance of insulin action and resistance (Fig. 1). In the context of energy metabolism, insulin promotes energy storage. In energy-surplus conditions, such as obesity and aging, insulin-sensitive cells develop insulin resistance because of mitochondrial overheating from the substrate overloading, which may cause mitochondrial dysfunction through ATP overproduction. The ATP concept is supported by the basic principle of biochemistry that substrates (e.g., glucose, fatty acids, and amino acids) induce the enzyme activity in the production of ATP, and ATP inhibits the mitochondrial production in a feedback manner. When ATP overproduction occurs in pancreatic islets, it triggers the hypersecretion of insulin in $\beta$-cells and glucagon in $\alpha$-cells to promote insulin resistance through intracellular and extracellular activities. Mitochondrial overheating may lead to mitochondrial dysfunction through the ATP suppression of mitochondrial biogenesis and mitophagy in the prevention of sustained ATP overproduction in the muscle. The mitochondrial dysfunction leads to insulin resistance to facilitate the downregulation of substrate overloading in the mitochondria. When the ATP overproduction is attenuated by the control of substrate overloading in weight loss by medicines, lifestyle changes, and bypass surgery, mitochondrial function is restored to normalize insulin sensitivity in cells. Insulin resistance is a protective cellular response to control the mitochondrial overheating by cutting down the substrate overloading in the mitochondria. The ATP-based concept is under debate for the lack of accurate detection of intracellular ATP level in vivo but is well supported by substantial basic and clinical studies. Given that ATP is required for normal cellular activities, the manipulation of ATP by drugs faces challenges because severe ATP deficiency is toxic to cells. Moreover, this manipulation is not allowed in the drug development for type 2 diabetes. ATP may explain the metformin activity with new mechanisms, such as inhibition of insulin and glucagon hypersecretion by islet.

\section{Acknowledgements}

This work is supported by the National Key R\&D Program of China (No. 2018YFA0800603). 


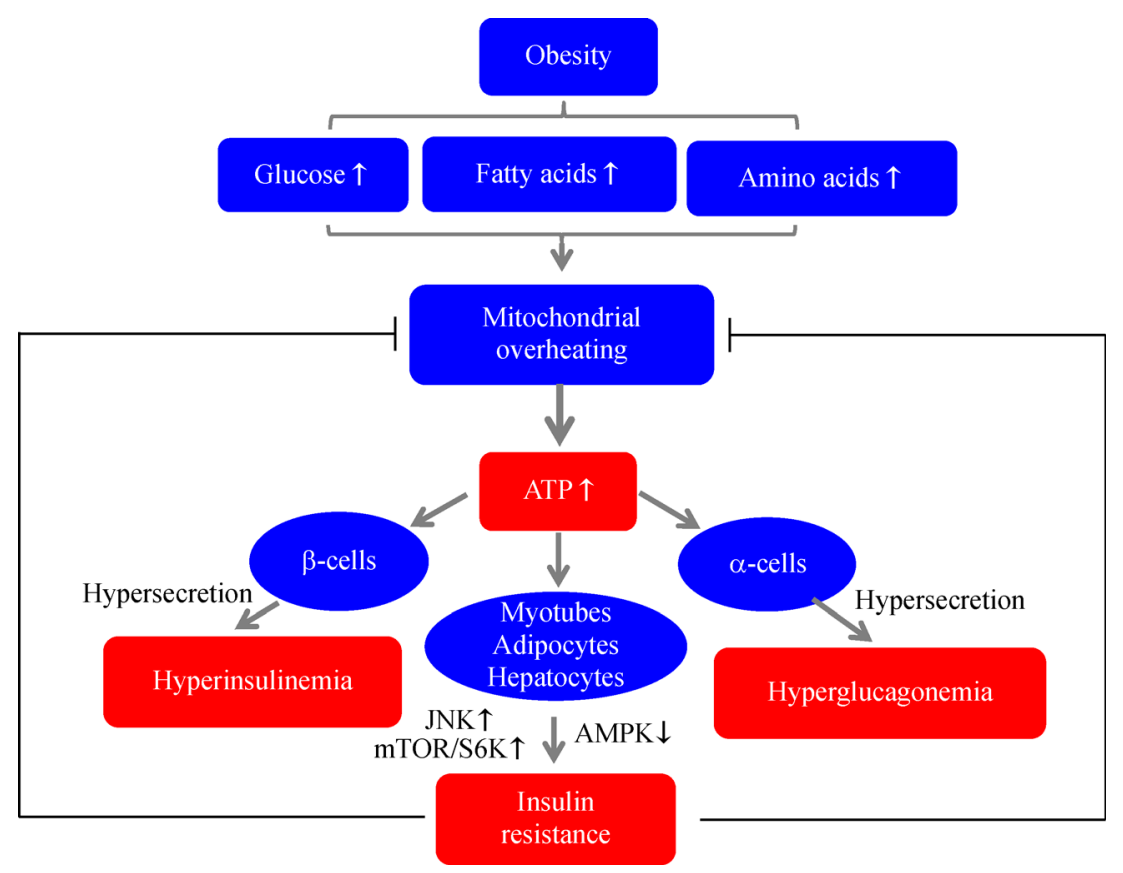

Fig. 1 ATP-based insulin resistance model.

\section{Compliance with ethics guidelines}

Jianping Ye declares no conflict of interest. This manuscript is a review article and does not involve a research protocol that requires the approval of relevant institutional review board or ethics committee.

Open Access This article is licensed under a Creative Commons Attribution 4.0 International License, which permits use, sharing, adaptation, distribution and reproduction in any medium or format, as long as you give appropriate credit to the original author(s) and the source, provide a link to the Creative Commons licence, and indicate if changes were made.

The images or other third party material in this article are included in the article's Creative Commons licence, unless indicated otherwise in a credit line to the material. If material is not included in the article's Creative Commons licence and your intended use is not permitted by statutory regulation or exceeds the permitted use, you will need to obtain permission directly from the copyright holder.

To view a copy of this licence, visit http://creativecommons.org/ licenses/by/4.0/.

\section{References}

1. Ye J. Mechanisms of insulin resistance in obesity. Front Med 2013; 7(1): 14-24

2. Sanchez-Garrido MA, Tena-Sempere M. Metabolic dysfunction in polycystic ovary syndrome: pathogenic role of androgen excess and potential therapeutic strategies. Mol Metab 2020; 35: 100937
3. Roden M, Shulman GI. The integrative biology of type 2 diabetes. Nature 2019; 576(7785): 51-60

4. Nikolic I, Leiva M, Sabio G. The role of stress kinases in metabolic disease. Nat Rev Endocrinol 2020; 16(12): 697-716

5. Lee YS, Wollam J, Olefsky JM. An integrated view of immunometabolism. Cell 2018; 172(1-2): 22-40

6. Goodman RP, Markhard AL, Shah H, Sharma R, Skinner OS, Clish CB, Deik A, Patgiri A, Hsu YH, Masia R, Noh HL, Suk S, Goldberger O, Hirschhorn JN, Yellen G, Kim JK, Mootha VK. Hepatic NADH reductive stress underlies common variation in metabolic traits. Nature 2020; 583(7814): 122-126

7. Zhang Y, Ye J. Mitochondrial inhibitor as a new class of insulin sensitizer. Acta Pharm Sin B 2012; 2(4): 341-349

8. Randle PJ, Garland PB, Hales CN, Newsholme EA. The glucose fatty-acid cycle. Its role in insulin sensitivity and the metabolic disturbances of diabetes mellitus. Lancet 1963; 281(7285): 785789

9. Hernández EA, Kahl S, Seelig A, Begovatz P, Irmler M, Kupriyanova Y, Nowotny B, Nowotny P, Herder C, Barosa C, Carvalho F, Rozman J, Neschen S, Jones JG, Beckers J, de Angelis $\mathrm{MH}$, Roden M. Acute dietary fat intake initiates alterations in energy metabolism and insulin resistance. J Clin Invest 2017; 127 (2): 695-708

10. Lee JH, Zhang Y, Zhao Z, Ye X, Zhang X, Wang H, Ye J. Intracellular ATP in balance of pro- and anti-inflammatory cytokines in adipose tissue with and without tissue expansion. Int J Obes 2017; 41(4): 645-651

11. Zhang Y, Zhao Z, Ke B, Wan L, Wang H, Ye J. Induction of posttranslational modifications of mitochondrial proteins by ATP contributes to negative regulation of mitochondrial function. PLoS One 2016; 11(3): e0150454

12. Qian S, Ma L, Peng S, Xu Y, Wu K, Shen S, Zhang X, Sun Y, Ye J. 
ATP reduces mitochondrial MECR protein in liver of diet-induced obese mice in mechanism of insulin resistance. Biosci Rep 2020; 40(6): BSR20200665

13. Le J, Zhang X, Jia W, Zhang Y, Luo J, Sun Y, Ye J. Regulation of microbiota-GLP1 axis by sennoside A in diet-induced obese mice. Acta Pharm Sin B 2019; 9(4): 758-768

14. Sun Y, Jin C, Zhang X, Jia W, Le J, Ye J. Restoration of GLP-1 secretion by Berberine is associated with protection of colon enterocytes from mitochondrial overheating in diet-induced obese mice. Nutr Diabetes 2018; 8(1): 53

15. Coughlan KA, Valentine RJ, Ruderman NB, Saha AK. Nutrient excess in AMPK downregulation and insulin resistance. J Endocrinol Diabetes Obes 2013; 1(1): 1008

16. Ruderman NB, Carling D, Prentki M, Cacicedo JM. AMPK, insulin resistance, and the metabolic syndrome. J Clin Invest 2013; 123(7): 2764-2772

17. Garcia D, Shaw RJ. AMPK: mechanisms of cellular energy sensing and restoration of metabolic balance. Mol Cell 2017; 66 (6): 789-800

18. Jiang P, Ren L, Zhi L, Yu Z, Lv F, Xu F, Peng W, Bai X, Cheng K, Quan L, Zhang X, Wang X, Zhang Y, Yang D, Hu X, Xiao RP. Negative regulation of AMPK signaling by high glucose via E3 ubiquitin ligase MG53. Mol Cell 2021; 81(3): 629-637.e5

19. Um SH, D'Alessio D, Thomas G. Nutrient overload, insulin resistance, and ribosomal protein S6 kinase 1, S6K1. Cell Metab 2006; 3(6): 393-402

20. Muoio DM. Metabolic inflexibility: when mitochondrial indecision leads to metabolic gridlock. Cell 2014; 159(6): 1253-1262

21. Koves TR, Ussher JR, Noland RC, Slentz D, Mosedale M, Ilkayeva O, Bain J, Stevens R, Dyck JR, Newgard CB, Lopaschuk GD, Muoio DM. Mitochondrial overload and incomplete fatty acid oxidation contribute to skeletal muscle insulin resistance. Cell Metab 2008; 7(1): 45-56

22. Qiao J, Chen C, Shangguan D, Mu X, Wang S, Jiang L, Qi L. Simultaneous monitoring of mitochondrial temperature and ATP fluctuation using fluorescent probes in living cells. Anal Chem 2018; 90(21): 12553-12558

23. Wang L, Yuan L, Zeng X, Peng J, Ni Y, Er JC, Xu W, Agrawalla BK, Su D, Kim B, Chang YT. A multisite-binding switchable fluorescent probe for monitoring mitochondrial ATP level fluctuation in live cells. Angew Chem Int Ed Engl 2016; 55(5): 17731776

24. Qian SN, Peng SQ, Zhang XY, Ye JP. Novel role of intracellular ATP in obesity pathology. Acta Physiol Sin (Sheng Li Xue Bao) 2020; 72(4): 532-538 (in Chinese)

25. Spinelli JB, Haigis MC. The multifaceted contributions of mitochondria to cellular metabolism. Nat Cell Biol 2018; 20(7): 745-754

26. Mollica MP, Iossa S, Liverini G, Soboll S. Stimulation of oxygen consumption following addition of lipid substrates in liver and skeletal muscle from rats fed a high-fat diet. Metabolism 1999; 48 (10): 1230-1235

27. Català-Niell A, Estrany ME, Proenza AM, Gianotti M, Lladó I. Skeletal muscle and liver oxidative metabolism in response to a voluntary isocaloric intake of a high fat diet in male and female rats. Cell Physiol Biochem 2008; 22(1-4): 327-336

28. Roesler A, Kazak L. UCP1-independent thermogenesis. Biochem J
2020; 477(3): 709-725

29. Chiumello D, Gotti M, Vergani G. Paracetamol in fever in critically ill patients - an update. J Crit Care 2017; 38: 245-252

30. Boden G, Jadali F, White J, Liang Y, Mozzoli M, Chen X, Coleman E, Smith C. Effects of fat on insulin-stimulated carbohydrate metabolism in normal men. J Clin Invest 1991; 88 (3): 960-966

31. Roden M, Price TB, Perseghin G, Petersen KF, Rothman DL, Cline GW, Shulman GI. Mechanism of free fatty acid-induced insulin resistance in humans. J Clin Invest 1996; 97(12): 28592865

32. Pagel-Langenickel I, Bao J, Pang L, Sack MN. The role of mitochondria in the pathophysiology of skeletal muscle insulin resistance. Endocr Rev 2010; 31(1): 25-51

33. Muoio DM. Intramuscular triacylglycerol and insulin resistance: guilty as charged or wrongly accused? Biochim Biophys Acta 2010; 1801(3): 281-288

34. Hao Z, Mumphrey MB, Townsend RL, Morrison CD, Münzberg $\mathrm{H}$, Ye J, Berthoud HR. Reprogramming of defended body weight after Roux-En-Y gastric bypass surgery in diet-induced obese mice. Obesity (Silver Spring) 2016; 24(3): 654-660

35. Khan RS, Bril F, Cusi K, Newsome PN. Modulation of insulin resistance in nonalcoholic fatty liver disease. Hepatology 2019; 70 (2): 711-724

36. Rena G, Hardie DG, Pearson ER. The mechanisms of action of metformin. Diabetologia 2017; 60(9): 1577-1585

37. Turner N, Li JY, Gosby A, To SW, Cheng Z, Miyoshi H, Taketo MM, Cooney GJ, Kraegen EW, James DE, Hu LH, Li J, Ye JM. Berberine and its more biologically available derivative, dihydroberberine, inhibit mitochondrial respiratory complex I: a mechanism for the action of berberine to activate AMP-activated protein kinase and improve insulin action. Diabetes 2008; 57(5): $1414-1418$

38. Yin J, Gao Z, Liu D, Liu Z, Ye J. Berberine improves glucose metabolism through induction of glycolysis. Am J Physiol Endocrinol Metab 2008; 294(1): E148-E156

39. Perry RJ, Kim T, Zhang XM, Lee HY, Pesta D, Popov VB, Zhang D, Rahimi Y, Jurczak MJ, Cline GW, Spiegel DA, Shulman GI. Reversal of hypertriglyceridemia, fatty liver disease, and insulin resistance by a liver-targeted mitochondrial uncoupler. Cell Metab 2013; 18(5): 740-748

40. Perry RJ, Zhang D, Zhang XM, Boyer JL, Shulman GI. Controlled-release mitochondrial protonophore reverses diabetes and steatohepatitis in rats. Science 2015; 347(6227): 1253-1256

41. Jiang H, Jin J, Duan Y, Xie Z, Li Y, Gao A, Gu M, Zhang X, Peng C, Xia C, Dong T, Li H, Yu L, Tang J, Yang F, Li J, Li J. Mitochondrial uncoupling coordinated with PDH activation safely ameliorates hyperglycemia via promoting glucose oxidation. Diabetes 2019; 68(12): 2197-2209

42. Luptak I, Sverdlov AL, Panagia M, Qin F, Pimentel DR, Croteau D, Siwik DA, Ingwall JS, Bachschmid MM, Balschi JA, Colucci WS. Decreased ATP production and myocardial contractile reserve in metabolic heart disease. J Mol Cell Cardiol 2018; 116: 106-114

43. Hesselink MK, Schrauwen-Hinderling V, Schrauwen P. Skeletal muscle mitochondria as a target to prevent or treat type 2 diabetes mellitus. Nat Rev Endocrinol 2016; 12(11): 633-645

44. Rovira-Llopis S, Bañuls C, Diaz-Morales N, Hernandez-Mijares 
A, Rocha M, Victor VM. Mitochondrial dynamics in type 2 diabetes: Pathophysiological implications. Redox Biol 2017; 11: 637-645

45. Sharma K. Mitochondrial hormesis and diabetic complications. Diabetes 2015; 64(3): 663-672

46. Zhang CS, Hawley SA, Zong Y, Li M, Wang Z, Gray A, Ma T, Cui J, Feng JW, Zhu M, Wu YQ, Li TY, Ye Z, Lin SY, Yin H, Piao HL, Hardie DG, Lin SC. Fructose-1,6-bisphosphate and aldolase mediate glucose sensing by AMPK. Nature 2017; 548(7665): $112-116$

47. González A, Hall MN, Lin SC, Hardie DG. AMPK and TOR: the yin and yang of cellular nutrient sensing and growth control. Cell Metab 2020; 31(3): 472-492

48. Herzig S, Shaw RJ. AMPK: guardian of metabolism and mitochondrial homeostasis. Nat Rev Mol Cell Biol 2018; 19(2): $121-135$

49. Hardie DG, Schaffer BE, Brunet A. AMPK: an energy-sensing pathway with multiple inputs and outputs. Trends Cell Biol 2016; 26(3): 190-201

50. Viollet B, Andreelli F, Jørgensen SB, Perrin C, Geloen A, Flamez D, Mu J, Lenzner C, Baud O, Bennoun M, Gomas E, Nicolas G, Wojtaszewski JF, Kahn A, Carling D, Schuit FC, Birnbaum MJ, Richter EA, Burcelin R, Vaulont S. The AMP-activated protein kinase $\alpha 2$ catalytic subunit controls whole-body insulin sensitivity. J Clin Invest 2003; 111(1): 91-98

51. Valero T. Mitochondrial biogenesis: pharmacological approaches. Curr Pharm Des 2014; 20(35): 5507-5509

52. Lowell BB, Shulman GI. Mitochondrial dysfunction and type 2 diabetes. Science 2005; 307(5708): 384-387

53. Kelley DE, Mandarino LJ. Fuel selection in human skeletal muscle in insulin resistance: a reexamination. Diabetes 2000; 49(5): 677683

54. Ye J. Role of insulin in the pathogenesis of free fatty acid-induced insulin resistance in skeletal muscle. Endocr Metab Immune Disord Drug Targets 2007; 7(1): 65-74

55. Zhang J, Gao Z, Yin J, Quon MJ, Ye J. S6K directly phosphorylates IRS-1 on Ser-270 to promote insulin resistance in response to TNF- $\alpha$ signaling through IKK2. J Biol Chem 2008; 283(51): 35375-35382

56. Newgard CB, An J, Bain JR, Muehlbauer MJ, Stevens RD, Lien LF, Haqq AM, Shah SH, Arlotto M, Slentz CA, Rochon J, Gallup D, Ilkayeva O, Wenner BR, Yancy WS Jr, Eisenson H, Musante G, Surwit RS, Millington DS, Butler MD, Svetkey LP. A branchedchain amino acid-related metabolic signature that differentiates obese and lean humans and contributes to insulin resistance. Cell Metab 2009; 9(4): 311-326

57. Zhang CS, Jiang B, Li M, Zhu M, Peng Y, Zhang YL, Wu YQ, Li TY, Liang Y, Lu Z, Lian G, Liu Q, Guo H, Yin Z, Ye Z, Han J, Wu JW, Yin H, Lin SY, Lin SC. The lysosomal v-ATPase-Ragulator complex is a common activator for AMPK and mTORC1, acting as a switch between catabolism and anabolism. Cell Metab 2014; 20 (3): $526-540$

58. Dennis PB, Jaeschke A, Saitoh M, Fowler B, Kozma SC, Thomas G. Mammalian TOR: a homeostatic ATP sensor. Science 2001; 294 (5544): 1102-1105

59. Corkey BE. Banting lecture 2011: hyperinsulinemia: cause or consequence? Diabetes 2012; 61(1): 4-13
60. Czech MP. Insulin action and resistance in obesity and type 2 diabetes. Nat Med 2017; 23(7): 804-814

61. Page MM, Johnson JD. Mild suppression of hyperinsulinemia to treat obesity and insulin resistance. Trends Endocrinol Metab 2018; 29(6): 389-399

62. Erion KA, Corkey BE. Hyperinsulinemia: a cause of obesity? Curr Obes Rep 2017; 6(2): 178-186

63. Shanik MH, Xu Y, Skrha J, Dankner R, Zick Y, Roth J. Insulin resistance and hyperinsulinemia: is hyperinsulinemia the cart or the horse? Diabetes Care 2008; 31(Suppl 2): S262-S268

64. Mehran AE, Templeman NM, Brigidi GS, Lim GE, Chu KY, Hu X, Botezelli JD, Asadi A, Hoffman BG, Kieffer TJ, Bamji SX, Clee SM, Johnson JD. Hyperinsulinemia drives diet-induced obesity independently of brain insulin production. Cell Metab 2012; 16(6): 723-737

65. Campbell JE, Newgard CB. Mechanisms controlling pancreatic islet cell function in insulin secretion. Nat Rev Mol Cell Biol 2021; 22(2): 142-158

66. Smith GI, Polidori DC, Yoshino M, Kearney ML, Patterson BW, Mittendorfer B, Klein S. Influence of adiposity, insulin resistance, and intrahepatic triglyceride content on insulin kinetics. J Clin Invest 2020; 130(6): 3305-3314

67. Gray SL, Donald C, Jetha A, Covey SD, Kieffer TJ. Hyperinsulinemia precedes insulin resistance in mice lacking pancreatic $\beta$ cell leptin signaling. Endocrinology 2010; 151(9): 4178-4186

68. Burnstock G. Purinergic signalling in endocrine organs. Purinergic Signal 2014; 10(1): 189-231

69. Hazama A, Hayashi S, Okada Y. Cell surface measurements of ATP release from single pancreatic $\beta$ cells using a novel biosensor technique. Pflugers Arch 1998; 437(1): 31-35

70. Hutton JC, Penn EJ, Peshavaria M. Low-molecular-weight constituents of isolated insulin-secretory granules. Bivalent cations, adenine nucleotides and inorganic phosphate. Biochem J 1983; 210(2): 297-305

71. Soberanes S, Misharin AV, Jairaman A, Morales-Nebreda L, McQuattie-Pimentel AC, Cho T, Hamanaka RB, Meliton AY, Reyfman PA, Walter JM, Chen CI, Chi M, Chiu S, GonzalezGonzalez FJ, Antalek M, Abdala-Valencia H, Chiarella SE, Sun KA, Woods PS, Ghio AJ, Jain M, Perlman H, Ridge KM, Morimoto RI, Sznajder JI, Balch WE, Bhorade SM, Bharat A, Prakriya M, Chandel NS, Mutlu GM, Budinger GRS. Metformin targets mitochondrial electron transport to reduce air-pollutioninduced thrombosis. Cell Metab 2019; 29(2): 335-347.e5

72. Yang X, Xu Z, Zhang C, Cai Z, Zhang J. Metformin, beyond an insulin sensitizer, targeting heart and pancreatic $\beta$ cells. Biochim Biophys Acta Mol Basis Dis 2017; 1863(8): 1984-1990

73. Kefas BA, Cai Y, Kerckhofs K, Ling Z, Martens G, Heimberg H, Pipeleers D, Van de Casteele M. Metformin-induced stimulation of AMP-activated protein kinase in $\beta$-cells impairs their glucose responsiveness and can lead to apoptosis. Biochem Pharmacol 2004; 68(3): 409-416

74. Carpentier J, Luyckx AS, Lefebvre PJ. Influence of metformin on arginine-induced glucagon secretion in human diabetes. Diabete Metab 1975; 1: 23-28

75. Wei X, Ke B, Zhao Z, Ye X, Gao Z, Ye J. Regulation of insulin degrading enzyme activity by obesity-associated factors and pioglitazone in liver of diet-induced obese mice. PLoS One 
2014; 9(4): e95399

76. Lee YH, Wang MY, Yu XX, Unger RH. Glucagon is the key factor in the development of diabetes. Diabetologia 2016; 59(7): 13721375

77. Finan B, Capozzi ME, Campbell JE. Repositioning glucagon action in the physiology and pharmacology of diabetes. Diabetes 2020; 69(4): 532-541

78. Dunning BE, Gerich JE. The role of $\alpha$-cell dysregulation in fasting and postprandial hyperglycemia in type 2 diabetes and therapeutic implications. Endocr Rev 2007; 28(3): 253-283

79. Miller RA, Chu Q, Xie J, Foretz M, Viollet B, Birnbaum MJ. Biguanides suppress hepatic glucagon signalling by decreasing production of cyclic AMP. Nature 2013; 494(7436): 256-260

80. Pettus JH, D'Alessio D, Frias JP, Vajda EG, Pipkin JD, Rosenstock J, Williamson G, Zangmeister MA, Zhi L, Marschke KB. Efficacy and safety of the glucagon receptor antagonist RVT-1502 in type 2 diabetes uncontrolled on metformin monotherapy: a 12-week doseranging study. Diabetes Care 2020; 43(1): 161-168

81. Cryer PE. Minireview: Glucagon in the pathogenesis of hypoglycemia and hyperglycemia in diabetes. Endocrinology 2012; 153 (3): 1039-1048

82. Wendt A, Birnir B, Buschard K, Gromada J, Salehi A, Sewing S, Rorsman P, Braun M. Glucose inhibition of glucagon secretion from rat alpha-cells is mediated by GABA released from neighboring $\beta$-cells. Diabetes 2004; 53(4): 1038-1045

83. Cabrera O, Jacques-Silva MC, Speier S, Yang SN, Köhler M, Fachado A, Vieira E, Zierath JR, Kibbey R, Berman DM, Kenyon NS, Ricordi C, Caicedo A, Berggren PO. Glutamate is a positive autocrine signal for glucagon release. Cell Metab 2008; 7(6): 545 554

84. Elliott AD, Ustione A, Piston DW. Somatostatin and insulin mediate glucose-inhibited glucagon secretion in the pancreatic $\alpha$ cell by lowering cAMP. Am J Physiol Endocrinol Metab 2015; 308 (2): E130-E143

85. Omar-Hmeadi M, Lund PE, Gandasi NR, Tengholm A, Barg S. Paracrine control of $\alpha$-cell glucagon exocytosis is compromised in human type-2 diabetes. Nat Commun 2020; 11(1): 1896

86. Liu R, Hong J, Xu X, Feng Q, Zhang D, Gu Y, Shi J, Zhao S, Liu W, Wang X, Xia H, Liu Z, Cui B, Liang P, Xi L, Jin J, Ying X, Wang X, Zhao X, Li W, Jia H, Lan Z, Li F, Wang R, Sun Y, Yang M, Shen Y, Jie Z, Li J, Chen X, Zhong H, Xie H, Zhang Y, Gu W, Deng X, Shen B, Xu X, Yang H, Xu G, Bi Y, Lai S, Wang J, Qi L, Madsen L, Wang J, Ning G, Kristiansen K, Wang W. Gut microbiome and serum metabolome alterations in obesity and after weight-loss intervention. Nat Med 2017; 23(7): 859-868

87. Simonson M, Boirie Y, Guillet C. Protein, amino acids and obesity treatment. Rev Endocr Metab Disord 2020; 21(3): 341-353

88. Burnstock G, Gentile D. The involvement of purinergic signalling in obesity. Purinergic Signal 2018; 14(2): 97-108

89. Antonioli L, Blandizzi C, Pacher P, Haskó G. The purinergic system as a pharmacological target for the treatment of immunemediated inflammatory diseases. Pharmacol Rev 2019; 71(3): 345-382

90. Giacovazzo G, Fabbrizio P, Apolloni S, Coccurello R, Volonté C. Stimulation of P2X7 enhances whole body energy metabolism in mice. Front Cell Neurosci 2019; 13: 390

91. Sun S, Xia S, Ji Y, Kersten S, Qi L. The ATP-P2X7 signaling axis is dispensable for obesity-associated inflammasome activation in adipose tissue. Diabetes 2012; 61(6): 1471-1478

92. Pérez-Sen R, Gómez-Villafuertes R, Ortega F, Gualix J, Delicado EG, Miras-Portugal MT. An update on $\mathrm{P}_{2} \mathrm{Y}_{13}$ receptor signalling and function. Adv Exp Med Biol 2017; 1051: 139-168

93. Cao X, Ye X, Zhang S, Wang L, Xu Y, Peng S, Zhou Y, Peng Y, Li J, Zhang X, Han X, Huang H, Jia W, Ye J. ADP induces blood glucose through direct and indirect mechanisms in promotion of hepatic gluconeogenesis by elevation of NADH. Front Endocrinol 2021; 12: 663530

94. Amisten S, Meidute-Abaraviciene S, Tan C, Olde B, Lundquist I, Salehi A, Erlinge D. ADP mediates inhibition of insulin secretion by activation of P2Y13 receptors in mice. Diabetologia 2010; 53 (9): 1927-1934

95. Enjyoji K, Kotani K, Thukral C, Blumel B, Sun X, Wu Y, Imai M, Friedman D, Csizmadia E, Bleibel W, Kahn BB, Robson SC. Deletion of cd39/entpd1 results in hepatic insulin resistance. Diabetes 2008; 57(9): 2311-2320

96. Jacques FJ, Silva TM, da Silva FE, Ornelas IM, Ventura ALM. Nucleotide P2Y13-stimulated phosphorylation of CREB is required for ADP-induced proliferation of late developing retinal glial progenitors in culture. Cell Signal 2017; 35: 95-106

97. Blom D, Yamin TT, Champy MF, Selloum M, Bedu E, CarballoJane E, Gerckens L, Luell S, Meurer R, Chin J, Mudgett J, Puig O. Altered lipoprotein metabolism in $\mathrm{P}_{2} \mathrm{Y}_{13}$ knockout mice. Biochim Biophys Acta 2010; 1801(12): 1349-1360

98. Petersen KF, Befroy D, Dufour S, Dziura J, Ariyan C, Rothman DL, DiPietro L, Cline GW, Shulman GI. Mitochondrial dysfunction in the elderly: possible role in insulin resistance. Science 2003; 300(5622): 1140-1142

99. Reznick RM, Zong H, Li J, Morino K, Moore IK, Yu HJ, Liu ZX, Dong J, Mustard KJ, Hawley SA, Befroy D, Pypaert M, Hardie DG, Young LH, Shulman GI. Aging-associated reductions in AMP-activated protein kinase activity and mitochondrial biogenesis. Cell Metab 2007; 5(2): 151-156

100. Houstis N, Rosen ED, Lander ES. Reactive oxygen species have a causal role in multiple forms of insulin resistance. Nature 2006; 440(7086): 944-948

101. Nair KS, Bigelow ML, Asmann YW, Chow LS, Coenen-Schimke JM, Klaus KA, Guo ZK, Sreekumar R, Irving BA. Asian Indians have enhanced skeletal muscle mitochondrial capacity to produce ATP in association with severe insulin resistance. Diabetes 2008; 57(5): 1166-1175 